This document is the accepted manuscript version of the following article:

Zhang, X., Witte, J., Schildhauer, T., \& Bauer, C. (2020). Life cycle assessment of power-togas with biogas as the carbon source. Sustainable Energy and Fuels, 4(3), 1427-1436.

https://doi.org/10.1039/C9SE00986H

\title{
ARTICLE
}

\section{Life cycle assessment of Power-to-Gas with biogas as carbon source}

Received 00th January 20xx, Accepted 00th January 20xx

DOI: $10.1039 / x 0 x \times 00000 x$

\section{Introduction}

As the penetration of wind and solar energy increases, the intermittent nature of these technologies imposes challenges to the energy system. Storage technologies like batteries can provide balancing for the mismatch of supply and demand from seconds up to a few hours. ${ }^{1}$ However, for countries with great seasonal difference in energy demand and renewable energy supply, very high penetration of intermittent renewables and ambitious plans of energy system decarbonization are likely to require long-term seasonal energy storage. ${ }^{2}$ Since the amount of energy that needs to be stored can be potentially large and the energy loss during storage has to be relatively low, only a few technologies can be deployed as seasonal energy storage. Options are pumped hydro storage, power-to-gas (P2G) and thermal energy storage. ${ }^{3,4}$

\footnotetext{
a. Laboratory for Energy Systems Analysis, Paul Scherrer Institute, Switzerland. ${ }^{b}$. Bioenergy and Catalysis Laboratory, Paul Scherrer Institute, Switzerland. Electronic Supplementary Information (ESI) available: [details of any supplementary information available should be included here]. See
} DOI: $10.1039 / x 0 x x 00000 x$
Pumped hydro storage is a very mature technology, but requires favourable site conditions, for which the exploitable potential in the future is rather limited in many regions, even by considering the recent retreat of glacier due to climate change. ${ }^{5}$ Similarly, the implementation of thermal energy storage might be limited by spatial constraints, as sensible thermal energy storage - the most mature technology - is often associated with lower energy density compared to latent heat storage, ${ }^{6}$ which prevents its wide deployment as seasonal storage. Therefore, P2G systems, which can convert electricity to gas, become attractive, as gas can be easily stored over long period of time without great loss of energy, and has more flexibility than electricity in terms of transport and usage.

Electrolysis can use electricity and split water into hydrogen and oxygen. To utilize the existing natural gas infrastructure for storage and transportation, hydrogen can further react with the carbon dioxide $\left(\mathrm{CO}_{2}\right)$ from various sources to produce synthetic natural gas (SNG) through methanation, and can be a substitute for fossil natural gas. However, whether the consumption of synthetic natural gas will have lower life cycle GHG emissions than fossil natural gas depends on the source of $\mathrm{CO}_{2}$ used for methanation. In 
general, utilizing $\mathrm{CO}_{2}$ from mineral or fossil sources can reduce overall system life cycle GHG emissions (i.e. the emissions from both systems where fossil $\mathrm{CO}_{2}$ is generated and utilized) by a maximum of $50 \%{ }^{7}$ But a previous study shows that, from a life cycle perspective, $\mathrm{CO}_{2}$ emissions of synthetic fuel combustion are much higher than all other contributions (e.g., embodied GHG emissions of material and energy supply for $\mathrm{CO}_{2}$ capture). ${ }^{8}$ Thus $\mathrm{CO}_{2}$ from biomass with short rotation periods (i.e. fast-growing biomass) is attractive, since it allows for a closed carbon cycle: combustion of SNG containing carbon from biogenic sources results in $\mathrm{CO}_{2}$ emissions equal to the $\mathrm{CO}_{2}$ sequestrated during the growth of biomass $^{9}$ and therefore, the system life cycle GHG emission reduction potential is higher.

Previous studies have investigated the technical and economic aspects of such P2G systems using biogenic carbon sources. Methanation of biogas can be conducted with both biological and catalytic methanation. Biological methanation in stirred bubble columns has reached pre-commercial pilot scale. ${ }^{10}$ The Biocat project has implemented a P2G system with $1 \mathrm{MW}$ electrolyser and a biological methanation using methanogenic archaea in Denmark. ${ }^{11}$ Catalytic methanation of biogas in adiabatic fixed bed reactors was tested at pilot scale in Denmark, ${ }^{12}$ a cooled fixed bed methanation reactor of $25 \mathrm{~kW}$ capacity was tested successfully at different biogas plants. ${ }^{13}$ Witte et al. demonstrated the feasibility of direct catalytic methanation of biogas in a fluidized bed reactor operating over 1100 hours. $^{14}$ Calbry-Muzyka et al. have demonstrated the gas cleaning processes required for the biogas from wastewater treatment plant and biowaste digestion, which is required to remove the $\mathrm{H}_{2} \mathrm{~S}$ and other trace sulphur compounds in order to avoid catalyst deactivation. ${ }^{15}$ A number of papers discuss the costs of methanation systems, ${ }^{1617181920}$ but come to quite different conclusions which can be traced back to differing boundary conditions and assumptions with respect to the auxiliary units needed for methanation. Witte et al. designed and simulated six different alternative systems for direct catalytic methanation of biogas in detail and analysed the techno-economic performance of diverse system variations. ${ }^{21,22}$

However, the life cycle environmental impacts of such systems were hardly covered in literature so far. Jentsch et al. pointed out the difference between biomass and fossil $\mathrm{CO}_{2}$ sources and their impact on overall life cycle greenhouse gas (GHG) emissions without quantitative discussion. ${ }^{23}$ This was then quantitatively elaborated in more details in the work of Zhang et al. by comparing the life cycle GHG emissions considering different $\mathrm{CO}_{2}$ sources, although there was no discussion on the systems of direct biogas methanation and the option of obtaining $\mathrm{CO}_{2}$ from biogas upgrading. ${ }^{8}$ Parra et al. considered the biogas upgrading as a $\mathrm{CO}_{2}$ source in a study that addresses both economic and environmental aspects. ${ }^{24}$ However, $\mathrm{CO}_{2}$ was considered as a waste product from biogas upgrading - in other words, it is assumed to be available free of environmental burdens and costs, and there was no

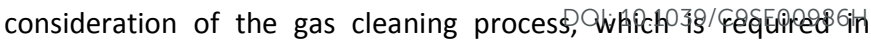
reality when using $\mathrm{CO}_{2}$ from biogas as a carbon source in a methanation process. Vo et al. performed LCA and technoeconomic analysis for using ex-situ biological methanation as biogas upgrading technology for grass and slurry treatment, and found that while such systems could achieve substantial GHG emission savings, the GHG emissions of electricity supply required must be very low and thus making such system unlikely to improve the sustainability of biogas upgrading. ${ }^{25,26}$ Wettstein et al. assessed P2G as a substitute technology in biogas upgrading ${ }^{27}$, while the project of Biocat has also conducted LCA of the biological methanation with wastewater treatment plant as the source of biogas, ${ }^{28}$ but both have not considered gas cleaning to treat the biogas before methanation, or any other processing to post-process the product gas for reaching equivalent natural gas quality, which is required in practice.

Collet et al. is the only study that looked so far into the life cycle costs and environmental impacts of chemical methanation by reacting hydrogen directly with biogas or $\mathrm{CO}_{2}$ separated from biogas upgrading in fixed-bed methanation. ${ }^{29}$ These methanation systems were then compared with two biogas upgrading technologies, particularly amine scrubbing and membrane separation, based on $1 \mathrm{MJ}$ of heat produced by the combustion of product gas in a gas boiler. However, this analysis could be improved with regard to several aspects:

- First, environmental credits due to the assumed substitution of conventional fertilizer by digestate - a by-product from anaerobic digestion of biomass feedstock - are accounted for. However, in practice, digestate will often not substitute conventional fertilizer depending on the composition of the feedstock and the applicable legal regulations. ${ }^{30}$ In fact, in countries like Switzerland, digestate from anaerobic digestion of sewage sludge is by law not allowed to be reused and has to be incinerated. ${ }^{31}$ In addition, depending on its properties, most often digestate also requires additional processing before it can be used as a substitute for fertilizer, which was not considered in the study.

- While the emissions from the use phase of digestate on agricultural fields were accounted for, the emissions from the use phase of conventional fertilizer were ignored - this is not consistent with the consideration of the production phase of digestate and fertilizer: the emissions of production for both digestate and fertilizer are considered, and the difference between the two is accounted as environmental credit. In other words, the comparison of alternatives was carried out based on inconsistent system scopes. 
- The technological difference in upgrading technologies and associated uncertainties vary to a great extent, e.g., the gas cleaning process before $\mathrm{CO}_{2}$ and biogas can be fed into the methanation process can be quite different depending on the properties of the product gas. ${ }^{32}$ It is not clear to which extent these differences were understood and considered in the study. The authors also mentioned that they performed a "prospective LCA of a process that does not yet exist", thus detailed processes involved in the systems might be subject to major system modifications based on understanding of more realistic systems (e.g., demonstrators).

To address these research gaps, we have assessed the same systems, ensuring the consistency of the system model and not taking into account the substitution of conventional fertilizer. We also create our LCA model building upon more realistic data based on an actual demonstration plant reflecting current technology performance. ${ }^{33}$ In addition, we have considered two types of suitable biomass, namely sewage sludge and green waste, and in case where biogas upgrading is needed, three upgrading technologies with specific performances are considered.

This paper is structured as follows: in the methodology and data section, we introduce the systems assessed, methodology applied and explain the key assumptions and input parameters used in the analysis. In the result section, we focus on the use of product gas as an alternative fuel for compressed natural gas (CNG) passenger vehicles, and compare its life cycle GHG emissions with those of other passenger vehicles on a common basis of 1 vehicle kilometre ( $\mathrm{vkm})$ distance travelled. Alongside with this comparison, major processes that contribute most to the overall life cycle GHG emissions are discussed. Last, in order to understand the potential contribution of applying such P2G systems for the decarbonization of the mobility sector, we take Switzerland as an example, considering its national potential of suitable biomass that can be used as feedstock, and estimate how much GHG emissions such P2G systems can save in comparison with fossil fuel alternatives. Next, we draw conclusions based on our analysis and compare our findings with those in the literature. We also discuss other alternative technologies that can utilize renewable electricity and compare these to our analysis on P2G. In the end, we summarize and point out the directions for future research.

\section{Methodology and Data}

Life cycle assessment (LCA) is a method that is used to quantify the potential environmental impacts throughout a product's or service's lifecycle: from raw material acquisition, product manufacturing, use, to end-of-life treatment, to recycling and disposal. ${ }^{34}$ Different from well-to-wheel or well-to-tank studies, which are often used in comparing multiple fuel options, LCA includes not only all energy flows along the chain from fuel extraction to fuel consumption, but also the acquisition of of other materials and their environmental burdens, lsuen material requirement for fuel production, facilities and infrastructure, etc. $^{35,36}$ In this study, three types of systems that produce gas with high concentration of methane $(>96 \%$, suitable to replace conventional natural gas) are assessed using attributional LCA, which accounts for the average, relevant environmental physical flows to and from a product system and its subsystems during its entire life cycle. ${ }^{37}$ The systems investigated include conventional biogas upgrading, methanation with $\mathrm{CO}_{2}$ from biogas upgrading, and direct biogas methanation technologies (Fig. 1). Biogas is generated from the anaerobic digestion of sewage sludge and green waste. Manure is not considered in this study as the distances between feedstock origin and place of use are limited due to economic considerations, ${ }^{38}$ which often prevents manure from being used as feedstock in a centralized system at the scale investigated in this study (1-2 MW electric power input to the electrolyser). Three conventional biogas upgrading technologies are analysed, including Pressure Swing Absorption (PSA), amine scrubbing and membrane separation, for which different energy consumptions and different leakage rates of methane are considered.
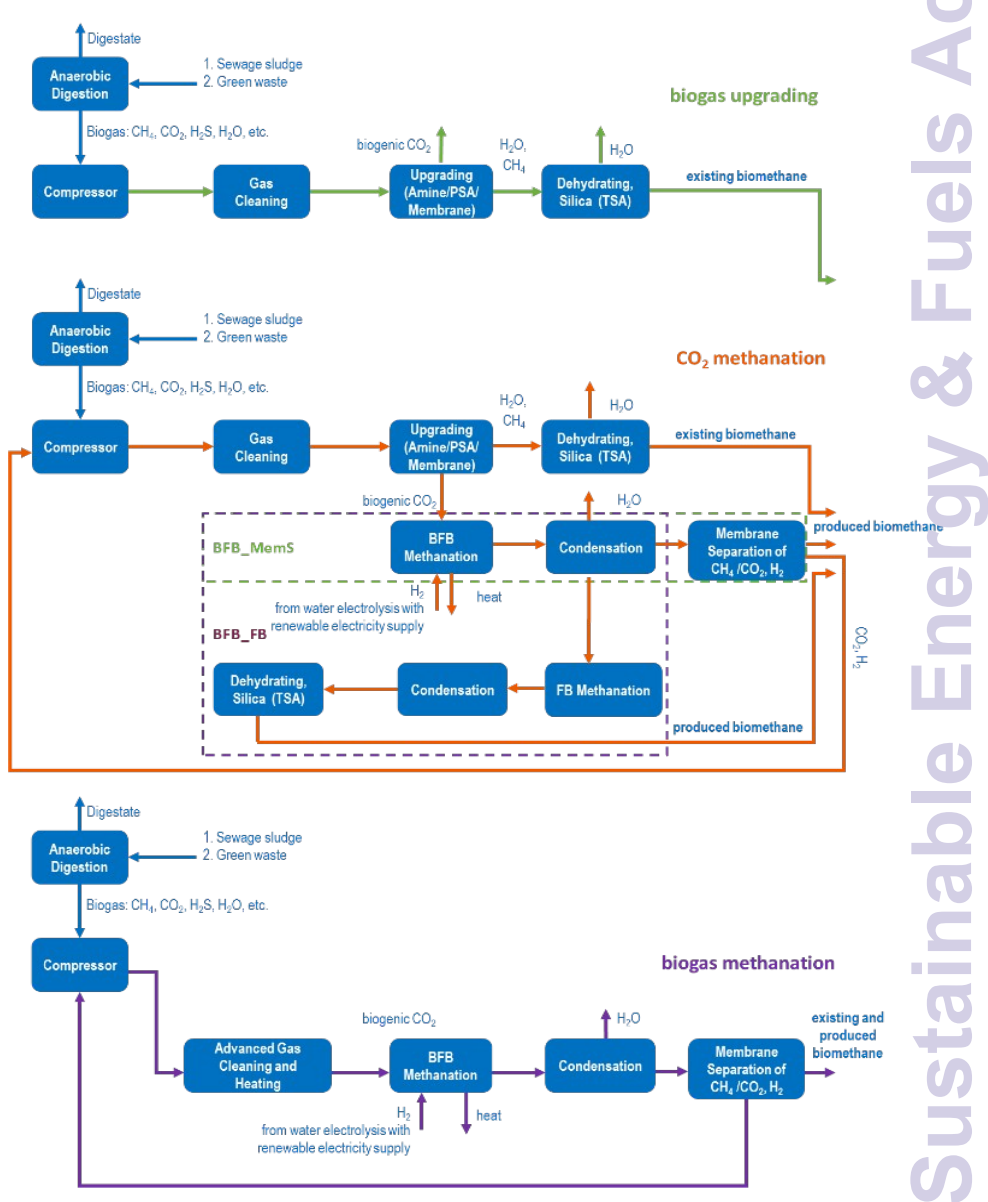

Fig. 1 System diagram of the three biomethane production systems considered in this study. From top to bottom: conventional biogas upgrading; methanation with $\mathrm{CO} 2$ separated from conventional biogas upgrading; direct biogas methanation (PSA: pressure swing adsorption; TSA: temperature swing adsorption; BFB: bubbling fluidized bed; FB: fixed bed; MemS: membrane system with single pressure level) 


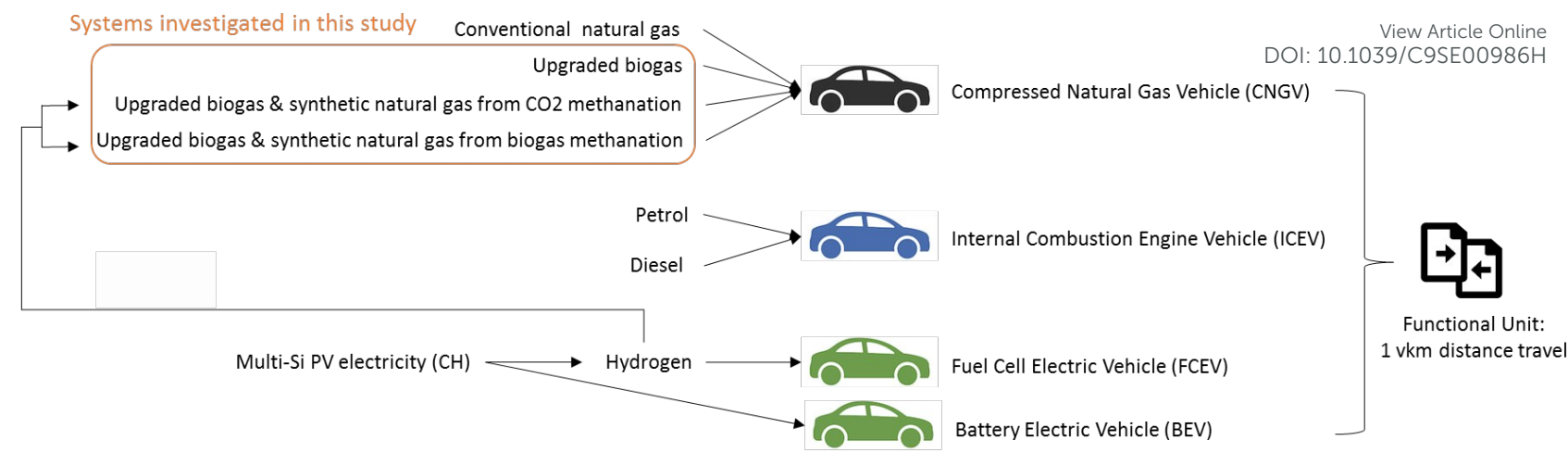

Fig. 2 Functional unit and alternatives for comparison

We assume the biomethane to be used as vehicle fuel. The functional unit in this study is $1 \mathrm{vkm}$ of distance travelled by an average mid-size CNG passenger vehicle. Based on the previous work of Cox et al., ${ }^{39}$ we compare these systems with a broader range of other vehicle types (Fig. 2; detailed assumption of different vehicle types including their lifetime, vehicle weight, fuel consumption, driving range, etc. are included in SI under Vehicle assumptions.docx), in order to get a comprehensive understanding about these systems being applied as alternative fuel production pathways for the mobility sector. Additionally, to get a high-level understanding on how such systems can help to decarbonize the mobility sector from a national perspective, we refer to the potential availability of suitable biomass in Switzerland, ${ }^{40}$ and estimate life cycle GHG emissions reduction such systems can provide compared with using conventional natural gas, as well as the corresponding amount of surplus renewable electricity sufficient for the production of hydrogen required in methanation. Different from Collet et al., ${ }^{29}$ we do not consider the substitution of conventional fertilizer by digestate from the anaerobic digestion due to the reasons explained above in the introduction. We focus on the current system performance and analysis given Swiss context (e.g. Swiss electricity supplies ${ }^{41}$ and availability of suitable biomass potential in Switzerland ${ }^{40}$ ).

Processes used in an LCA can be separated into foreground and background processes. The foreground data represent the processes of the system under investigation, and are collected for the purpose of the specific LCA. Background data is more generic data used for modelling the remaining activities. Ecoinvent version v3.4, system model "Allocation, cut-off by classification", is used as background database, as recommended for attributional LCA ${ }^{41}$. Therefore, biogas from anaerobic digestion is considered as burdenfree, because it is a product from the treatment process of waste and the burdens are allocated to the treatment service. ${ }^{42}$ The foreground Life Cycle Inventory (LCI) datasets in this study are transparently provided in the Supplementary Information (SI). A python-based open-source LCA analytical framework Brightway is used, $^{43}$ and together with the Jupyter Notebook (available in SI) that imports the foreground datasets and generates the results, the reproducibility of this study is ensured. The systems analysed for biomethane generation are illustrated in Fig. 1.

The impact category assessed in this study is impacts on climate change, based on the global warming potentials published in IPCC $2013,{ }^{44}$ as implemented in ecoinvent v3.4. ${ }^{45}$ Biogenic $\mathrm{CO}_{2}$ emissions are not accounted for assuming a closed carbon circle. However, biogenic methane and carbon monoxide emissions have to be accounted for. Because the source of carbon is biomass, global warming potentials for non-fossil methane and carbon monoxide emissions are used (at 28.5 and $2.5 \mathrm{~kg} \mathrm{CO}_{2}$ equivalents (eq) per $\mathrm{kg}$ of emissions, respectively), which are lower than their fossil counterparts ( 29.7 and $4.1 \mathrm{~kg} \mathrm{CO}_{2}$ eq per kg of emissions).

Detailed assumptions for each process step in the biomethane generation chain are listed below:

\section{Anaerobic digestion of waste}

Green waste and sewage sludge are considered as potential feedstocks for the anaerobic digestion process. The difference in green waste and sewage sludge lies in the fractions of $\mathrm{CH}_{4}$ and $\mathrm{CO}_{2}$ in biogas: The methane content of biogas produced from sewage is about $67 \%$ (vol-\%), whereas the methane content of biogas from green waste is about $54 \%$; similarly, $\mathrm{CO}_{2}$ contents of biogas from sewage sludge and green waste are about 32\% and 45\%, respectively. The nitrogen content is about the same in biogas produced from both types of waste, at $0.7 \%$. Ecoinvent datasets "treatment of sewage sludge by anaerobic digestion, $\mathrm{CH}$ " and "treatment of biowaste by anaerobic digestion, $\mathrm{CH}^{\mathrm{C}}$ are used. Since the cut-off system model is applied, biogas from both of these two waste treatment processes is "free-of-burden", as it is considered as a by-product of the waste treatment activities. Environmental burdens are entirely allocated to the treatment of sewage sludge and green waste, respectively, which are considered as "reference products".

Biogas upgrading 
In biogas upgrading, the key assumptions for three different biogas upgrading technologies are listed in Table 1.

Table 1 Assumptions in biogas upgrading technologies based on: $32,41,46,47,48 . \mathrm{Nm}^{3}$ in unit refers to the volume of upgraded biogas, i.e. biomethane under Standard Temperature and Pressure (STP) of $273.15 \mathrm{~K}$ and $1 \mathrm{~atm}$

\begin{tabular}{llll}
\hline & PSA & $\begin{array}{l}\text { Amine } \\
\text { scrubbing }\end{array}$ & Membrane \\
\hline $\begin{array}{l}\text { Share of } \mathrm{CH}_{4} \text { in } \\
\text { upgraded biogas }\end{array}$ & $96 \%$ & $99 \%$ & $98 \%$ \\
\hline $\begin{array}{l}\text { Share of } \mathrm{CO}_{2} \text { in } \\
\text { upgraded biogas }\end{array}$ & $2 \%$ & $1 \%$ & $2 \%$ \\
\hline $\begin{array}{l}\text { Share of } \mathrm{N}_{2} \text { in } \\
\text { upgraded biogas }\end{array}$ & $1 \%$ & - & - \\
\hline $\begin{array}{l}\text { Emission of hydrogen } \\
\text { sulfide }\left(\mathrm{kg} / \mathrm{Nm}^{3}\right)\end{array}$ & $3.5 \mathrm{E}-6$ & $3.5 \mathrm{E}-6$ & $3.5 \mathrm{E}-6$ \\
\hline $\begin{array}{l}\text { Emission of sulfur } \\
\text { dioxide }\left(\mathrm{kg} / \mathrm{Nm}^{3}\right)\end{array}$ & $5.2 \mathrm{E}-4$ & $5.5 \mathrm{E}-4$ & $5.5 \mathrm{E}-4$ \\
\hline $\begin{array}{l}\text { Leakage of } \\
\text { biomethane } \\
\left(\mathrm{kg} / \mathrm{Nm}^{3}\right)\end{array}$ & $1.3 \mathrm{E}-2^{\sim} 4.3 \mathrm{E}-2$ & $2.9 \mathrm{E} \sim 4-7.2 \mathrm{E}-4$ & $7.2 \mathrm{E}-4 \sim 3.6 \mathrm{E}-4$ \\
\hline $\begin{array}{l}\text { Electricity } \\
\text { consumption } \\
\left(\mathrm{kWh} / \mathrm{Nm}^{3}\right)\end{array}$ & & & \\
\hline $\begin{array}{l}\text { Heat consumption } \\
\left(\mathrm{kWh} / \mathrm{Nm}^{3}\right)\end{array}$ & - & $0.12-0.27$ & $0.2-0.34$ \\
\hline $\begin{array}{l}\text { Water consumption } \\
\left(\mathrm{m}^{3} / \mathrm{Nm}^{3}\right)\end{array}$ & - & & \\
\hline & & $0.55-0.65$ & - \\
\hline
\end{tabular}

\section{Electrolysis}

Water electrolysis technologies are classified into three categories based on the applied electrolyte: alkaline water electrolysis, proton exchange membrane (PEM) water electrolysis, and solid oxide water electrolysis. PEM electrolysis is applied in the system of this study to produce hydrogen, which is required for the methanation in the next step. PEM water electrolysis is chosen because of its several advantages over the other two electrolysis technologies, including higher rate of hydrogen production and more compact design. ${ }^{49}$ The $\mathrm{LCl}$ data for PEM electrolysis are taken from previous work of some of the authors. ${ }^{50}$ Electricity consumed in electrolysis is assumed to be produced from roof-top multi-silicon solar photovoltaics in Switzerland, due to its highest potential among other types of renewable electricity in the country. ${ }^{51}$ The ecoinvent dataset "electricity production, photovoltaic, $3 \mathrm{kWp}$ slanted-roof installation, multi-Si, panel, mounted, $\mathrm{CH}^{\prime \prime}$ is used to present electricity supply for electrolysis, since multi-crystalline silicon modules currently dominate the PV market.

\section{Methanation}

Data for the methanation process are obtained from the work of Witte et al. and Zhang et al. . ${ }^{22,50}$ Two types of system variations are considered: 1) bubbling fluidized bed with fixed bed methanation;

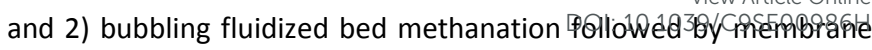
gas separation (Fig. 1, middle). The first reactor in both processes is a compact fluidized bed reactor with high conversion rate from $\mathrm{CO}_{2}$ to $\mathrm{CH}_{4}$. But due to thermodynamic equilibrium limitation, the low content of hydrogen and not sufficiently high enough content of methane in the product gas will limit its potential to be injected into the natural gas grid. Therefore, unreacted hydrogen and $\mathrm{CO}_{2}$ have to be separated from the product gas by a membrane, and recycled to the main reactor. Alternatively, water produced during methanation is separated by condensation, which shifts the thermodynamic equilibrium and allows for higher conversion in a second fixed bed methanation reactor. In the results, the differences between these two system variations are however found to be negligible, due to the low contribution of facilities in life cycle GHG emissions. Thus, for simplicity reason, the results are always shown for the latter system (BFB_MemS as shown in Fig. 1).

\section{Gas cleaning and processing}

As shown in Fig. 1, different gas cleaning and processing are required in the system. In conventional biogas upgrading (Fig. 1, top), first the biogas generated from anaerobic digestion is compressed, followed by a gas cleaning with activated carbon, which is impregnated in potassium iodide. Electricity consumption for biogas compression is different depending on the upgrading technologies, and is listed in Table 1. The upgraded biogas will go through further dehydration with silica and Temperature Swing Adsorption (TSA), before it is finally produced and ready to be used. $\mathrm{CO}_{2}$ separated from biogas upgrading is in this case released to the atmosphere.

If $\mathrm{CO}_{2}$ separated from biogas upgrading process is captured and stored for the following methanation, the steps before biogas upgrading are the same as conventional biogas upgrading. However, starting from methanation, there are two options of systems to be applied: one with bubbling fluidized bed reactor followed by membrane gas separation, and the other with bubbling fluidized bed reactor followed by a fixed-bed methanation reactor, condensation and dehydration (Fig. 1, middle). Remaining gas from membrane gas separation will be fed back to the compressor before the biogas upgrading process, in order to avoid the loss of hydrogen, $\mathrm{CO}_{2}$ that can further react and produce methane. The product gas from this system in the end is upgraded biomethane combined with the synthetic methane produced.

When biogas from anaerobic digestion directly reacts with hydrogen in methanation, a more advanced gas cleaning process is required than conventional biogas upgrading. This is because the catalyst in methanation will be deactivated if the sulphur content of the biogas is above a threshold. In the advanced gas cleaning process, bulk $\mathrm{H}_{2} \mathrm{~S}$ removal by cheap sorbents in presence of 
siloxanes, terpenes and humidity has to be combined with an specialized sorbent polishing the trace amounts of organic Sulphur species.

Application of biomethane and conventional natural gas in CNG vehicle and other types of vehicle

When the product gas is consumed in an average mid-size passenger CNG vehicle, it is assumed that the consumption of produced gas required per vkm distance travelled is 0.076 normal cubic meter. ${ }^{52,39}$ The composition of the biomethane from biogas upgrading is listed in Table 1. In the system of biogas methanation, the percentage of methane in the produced synthetic natural gas is about $98 \%$. Biomethane generated from all system options is considered to meet the required specifications for injection to the natural gas grid. We therefore assume that it can replace natural gas on a 1:1 basis and that vehicle performance will not be affected. The conventional natural gas supply is represented by using a dataset from ecoinvent v3.4, namely "market for natural gas, from high pressure network (1-5 bar), at service station, GLO". ${ }^{41}$

\section{Results}

A detailed breakdown of contributions and potential influential aleatory uncertainties (shown by error bars representing ranges of electricity consumption, biomethane leakage in biogas upgrading found in literature and the types of electricity consumed in electrolysis, respectively) for fuel production are shown and compared with conventional natural gas supply in Fig. 3. It shows that only biogas upgraded through membrane and amine scrubbing has lower life cycle GHG emissions than the production of conventional natural gas. In biogas upgrading, the determining factor of overall GHG emissions is the leakage of methane, which is determined by the biogas upgrading technology applied. Compared to methane leakage, uncertainty and contribution of the life cycle GHG emissions caused by the consumption of electricity in upgrading is insignificant. The GHG emissions of methanation pathways per unit of biomethane are higher than those of pure biogas upgrading, mainly because of the GHO empissions asEBepated with the electricity supply to the upstream production of hydrogen. The life cycle GHG emissions of electricity consumption are the main contributor in water electrolysis, while electrolysis facilities play rather minor role. ${ }^{8}$ In this case, impacts on climate change are caused by the manufacturing of multi-silicon solar photovoltaics panels upstream of the PV electricity production. This also means that using electricity with lower GHG intensity, such as wind and hydro power, will further reduce the GHG emissions of hydrogen production by $78 \%$ and $95 \%$ respectively (with the use of hydro power being illustrated in Fig. 3 , since it results in higher emission reduction potential), making it more competitive with biogas upgrading. Methanation of pure $\mathrm{CO}_{2}$ separated from biogas $\left(\mathrm{CO}_{2}\right.$ methanation) has higher GHG emissions than direct biogas methanation without prior $\mathrm{CO}_{2}$ separation, because there is biomethane leakage to the atmosphere in the $\mathrm{CO}_{2}$ separation step through biogas upgrading (shown by category "upgraded biogas and $\left.\mathrm{CO}_{2}{ }^{\prime \prime}\right)$. This is however lower than the methane leakage in the biogas upgrading pathways, as less upgraded biogas is produced in the $\mathrm{CO}_{2}$ methanation pathways (part of the product gas is synthetic methane from methanation), thus the corresponding leakage of biomethane contributes with a lower fraction. The type of biowaste also plays a role in the methanation pathways, because the percentage of biomethane in the biogas is triggered by the properties of waste feedstock, which will further determine the amount of hydrogen needed for methanation in order to produce a unit of biomethane. The results also show the contributions of GHG emissions from the construction of facilities and consumption of other material, such as catalyst, materials for gas cleaning process, methanation reactor, etc., are almost negligible.

To understand the impact of such systems producing alternative fuel for a passenger vehicle, Fig. 4 shows the life cycle GHG emissions per vkm distance travelled by a CNG vehicle powered by: 1) upgraded biogas, 2) mixture of upgraded biogas and synthetic

$\mathrm{kg}$ of $\mathrm{CO}_{2}$ eq/ $\mathrm{Nm} 3$ of natural gas or synthetic natural gas production

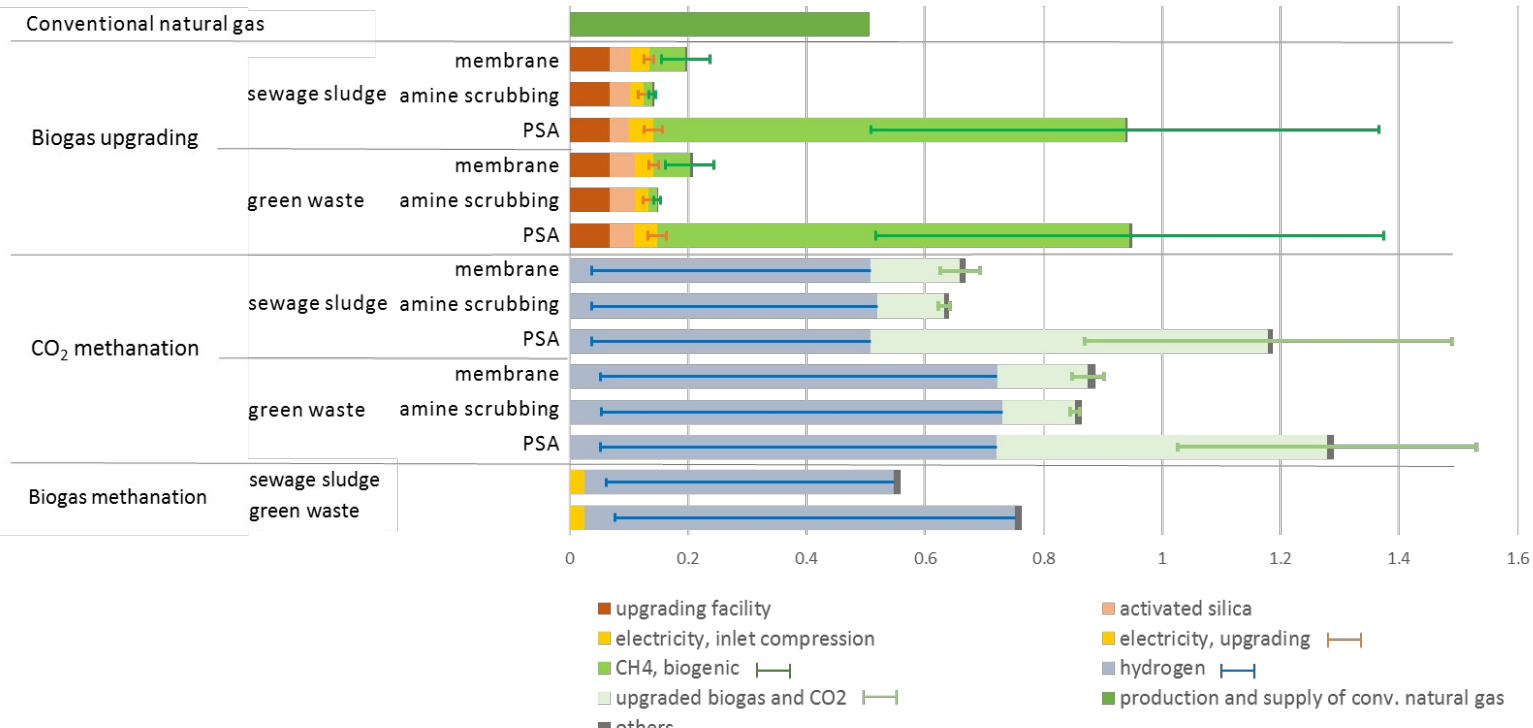

6 J. NameFig. 3 Life cycle GHG emissions breakdown of fuel production. The potential influential uncertainties of emissions are shown with er ror bars for selectedy $20 x x$ contributions: "hydrogen" (electricity fed into electrolysis produced from run-of-river hydro power plants in Switzerland), "electricity, upgrading" (range of electricity consumption in biogas upgrading), " $\mathrm{CH}_{4}$, biogenic" (range of biomethane leakage in biogas upgrading) and "upgraded biogas and $\mathrm{CO}_{2}$ " (including biomethane leakage in biogas upgrading). "others" include insignificant contributions of GHG emissions from construction of methanation reactor, required catalyst and other chemicals required in methanation, membrane, amine for $\mathrm{CO}_{2}$ capture and water consumption. 
natural gas produced from methanation with $\mathrm{CO}_{2}$ separated from biogas upgrading, 3) mixture of biomethane (existing in biogas) and synthetic natural gas produced from direct biogas methanation. It shows that the differences in terms of life cycle GHG emissions between these options mainly come from the contributions of fuel production (energy chain), as fuels are consumed in the same type of vehicle. The error bars show the uncertainty of emissions caused by different biogas upgrading technologies, in which the uncertainty of emissions is the highest when biogas is upgraded through PSA, because of its wide range of potential methane emissions and electricity consumption as shown in Table 1, which is shown in more detailed breakdowns in Fig. 4. When membrane or amine scrubbing biogas upgrading are applied, the emissions of the systems that only produce upgraded biogas are the lowest, because there is no need for hydrogen generation from electrolysis upstream. In case the hydrogen would be produced from electricity associated with very low GHG intensity, e.g. hydropower, greenhouse gas emissions as in the upgrading case can be achieved. Moreover, the methanation step increases the yield of biomethane, i.e. more vehicle fuel can be provided with the same amount of biomass feedstock.

When comparing the average GHG emissions of these systems with a CNG vehicle fuelled by conventional natural gas, using upgraded biogas results in $38-62 \%$ lower emissions, while biomethane from methanation pathways have $27 \%-50 \%$ lower emissions. This is because the direct GHG emissions are almost negligible in these systems, as the biogenic $\mathrm{CO}_{2}$ emitted after biomethane combustion biomethane fuelled CNG cars are comparable with a battery electric

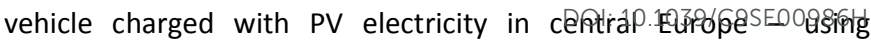
upgraded biogas without major $\mathrm{CH}_{4}$ leakage performs slightly better, methanation-based biomethane slightly worse. Compared to internal combustion engine vehicles fuelled by petrol, diesel or natural gas, substantial reduction of GHG emissions can be achieved by using biomethane.

Although the GHG emissions of biogas upgrading pathways are lower than those systems involving methanation, the $\mathrm{CO}_{2}$ of biogenic origin is emitted and not utilized after biogas is upgraded. Emitting this biogenic carbon, which is a limited resource, to the atmosphere will reduce the emission reduction potential of this technology from the overall system perspective (assuming biomethane would substitute fossil fuels). According to a study on the biomass resource potentials in Switzerland, ${ }^{40}$ the sustainable national potentials (i.e. a realistic potential that considers a range of technical, economic, political, legal and environmental constraints on top of the theoretical potential, which is purely based on the annual amount of biomass available $)^{51}$ for sewage sludge and green waste are 8.7 and 1.1 million tons in wet weight, respectively. To convert these biomass potentials to the amount of biogas and biomethane that can be generated, we used conversion factors consistent with the waste properties in ecoinvent if necessary. In this case, a wet weight density of sewage sludge of $721 \mathrm{~kg} / \mathrm{m}^{3}$ is used, whereas no conversion is needed for green waste, as the amount of waste feedstock in ecoinvent is already in mass unit. To estimate the maximum potential influence the systems investigated
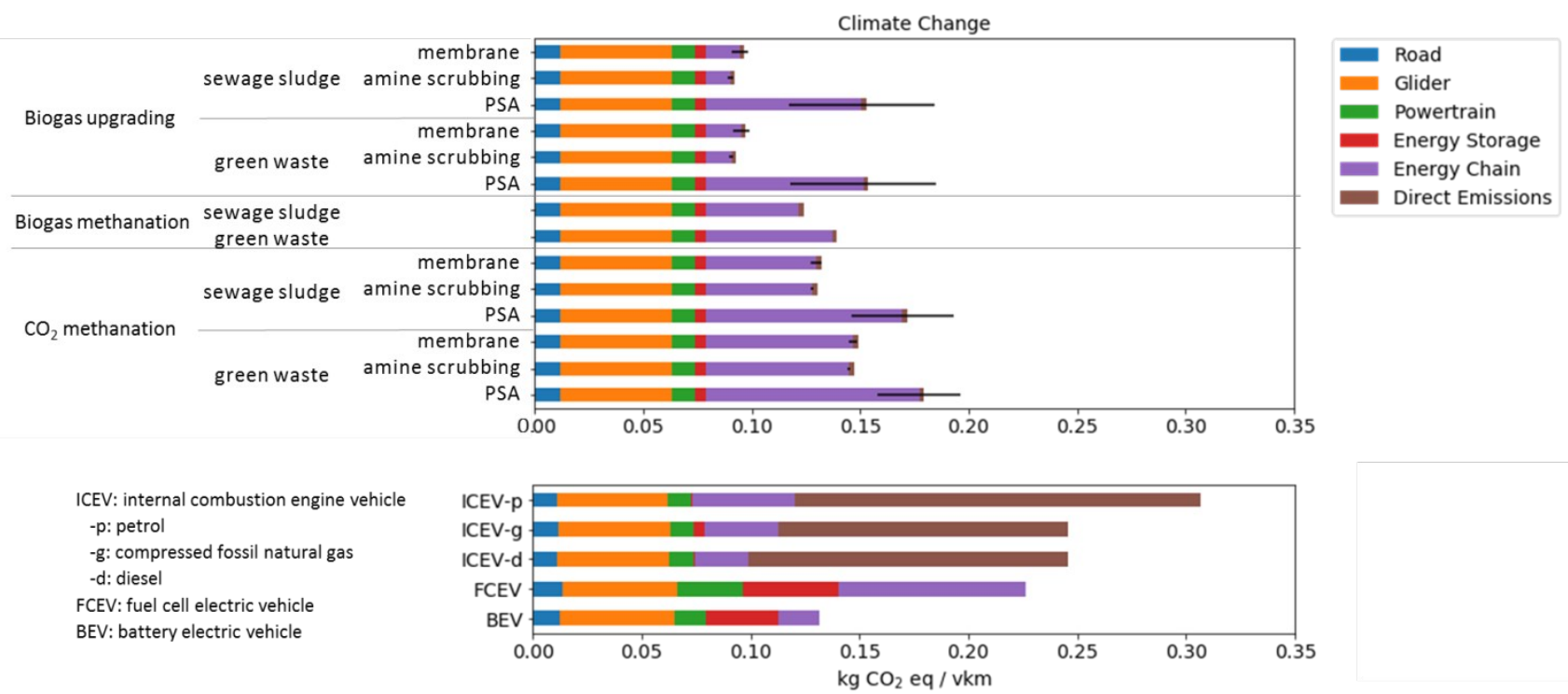

Fig. 4 Life cycle GHG emissions per vkm of distance travelled by: CNG passenger vehicle using synthetic natural gas (biomethane) and/or upgraded biogas (top); other passenger vehicles using fossil fuels and electricity or hydrogen (bottom). Electricity consumed in electrolysis for hydrogen production (as input for methanation and the fuel cell electric vehicle) and electricity for charging battery electric vehicles is produced from roof-top multi-silicon solar photovoltaic panels in Switzerland. The error bars show the variability of emissions caused by different biogas upgrading technologies.

in the vehicle is equivalent to the $\mathrm{CO}_{2}$ uptake during the growth of biomass - i.e. the natural carbon cycle is closed. Comparing with other vehicle types and fuel options, the life-cycle GHG emissions of can have in the decarbonisation of mobility sector, this potential is further converted to the annual travel distance that available biomethane would allow, given that the sustainable potentials of 
sewage sludge and green waste are fully utilized for biomethane production and used as vehicle fuels.

Depending on the biomethane production pathway selected, about 2.6 to 4.1 billion kilometers of distance can be travelled by fuels produced by the systems investigated in this study. Given the average annual travel distance of $12^{\prime} 000 \mathrm{~km}$ per vehicle and about 4.5 million private passenger vehicles in Switzerland in $2015,{ }^{53}$ this corresponds to $5 \%$ to $8 \%$ of annual distance travelled by all private passenger vehicles nation-wide. If the life cycle GHG emissions from CNG passenger vehicles with conventional natural gas were considered the baseline, the alternative biomethane production systems investigated in this study would allow for about 0.25-0.45 methanation system chosen. This means that the electricity used in

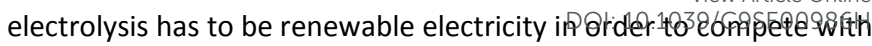
conventional natural gas in terms of life cycle emissions. This breakeven value is much higher than the one estimated by Reiter et al. for power-to-methane, at 73-113 $\mathrm{g} \mathrm{CO}_{2}$ eq per kWh of electricity, ${ }^{56}$ because in our analysis, the existing biomethane in biogas is utilized and included in the system boundary, whereas in Reiter et al., existing biomethane in biogas is not considered and pure $\mathrm{CO}_{2}$ is supplied as a waste from biogas upgrading, thus requiring more hydrogen to produce the same amount of biomethane.

In addition, different from the conclusions from the previous study which shows almost no difference between system options of

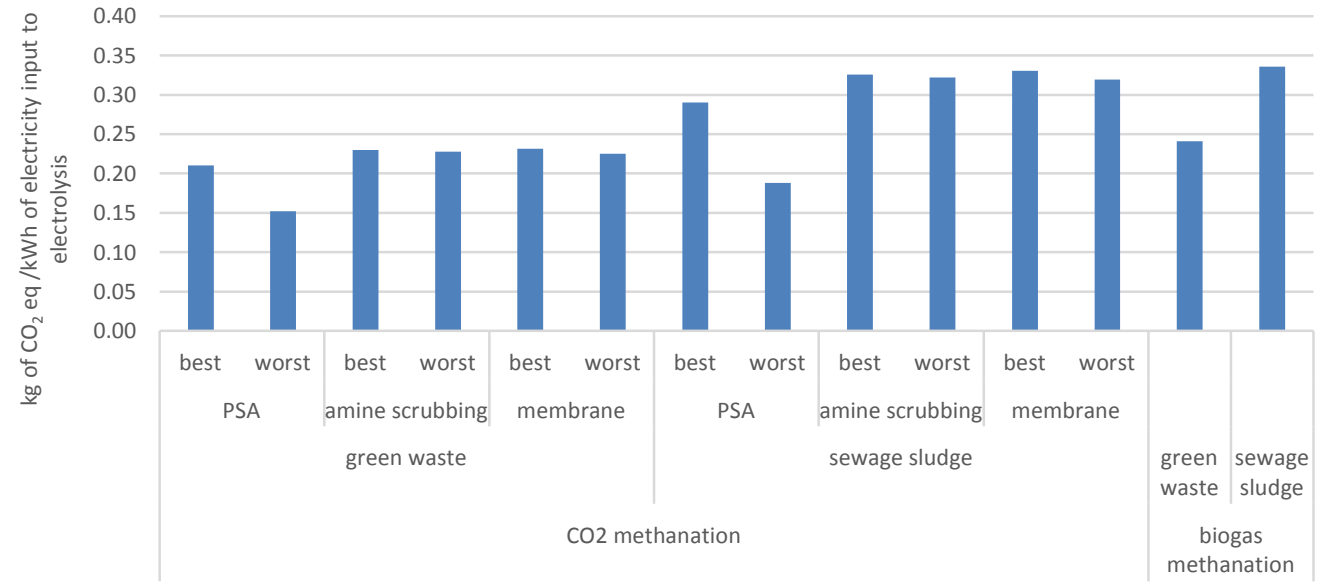

Fig. 5 Break-even points for life cycle GHG emissions compared to a natural gas car for embedded emissions in electricity input to electrolysis used for hydrogen supply to methanation pathways.

million tons of $\mathrm{CO}_{2}$ eq emission reduction per year. This corresponds to about $1 \%$ to $3 \%$ of $\mathrm{GHG}$ emissions within the mobility sector in Switzerland. ${ }^{54}$ However, in case of methanation pathways, electricity is also required to produce hydrogen in electrolysis - about 2.2 to $2.3 \mathrm{TWh}$ per year, which is approximately $4 \%$ of the current annual electricity consumption of 57.6 TWh in Switzerland in $2018 .^{55}$ If the life cycle GHG emissions from passenger vehicles with internal combustion engines and petrol as fuel are considered to be the baseline, the savings of GHG emissions will be increased, but still at the same order of magnitude, with less than 0.7 million tons $\mathrm{CO}_{2}$ eq, corresponding to $5 \%$ of GHG emissions of mobility sector in Switzerland per year. ${ }^{54}$

\section{Discussion}

Due to the main contribution of emissions associated with the electricity consumption in electrolysis, using electricity of low GHG emissions in electrolysis is key for low system GHG emissions of biomethane generation from methanation. To have lower emissions than the production and combustion of conventional natural gas, the life cycle GHG emissions of electricity supply in electrolysis has to be lower than 152-336 g of $\mathrm{CO}_{2}$ eq per $\mathrm{kWh}$ (as shown in Error! Reference source not found.), depending on the methanation, and only insignificant difference between methanation and biogas upgrading in terms of GHG emissions, ${ }^{29}$ the results of this study show much higher difference between system alternatives (Fig. 4). This is because the previous study has not considered the leakage of biomethane in the process of biogas upgrading. It also has different system scope by considering the emissions from digestate utilization and avoided burdens of potentially substituted fertilizer production.

Comparison of sew age sludge and green waste with other previously investigated non-biogenic $\mathrm{CO}_{2}$ sources (e.g., $\mathrm{CO}_{2}$ captured from cement or fossil fuel power plants) for methanation can be made avoiding allocation of $\mathrm{CO}_{2}$ streams on a system level on the basis of $1 \mathrm{kWh}$ of electricity input to electrolysis. ${ }^{50}$ Using biowaste as $\mathrm{CO}_{2}$ source can achieve much higher emission reductions. This is a result of less hydrogen needed for methanation (for the same amount of methane produced from the system) due to existing biomethane in the biogas and the biogenic origin of the $\mathrm{CO}_{2}$, which allows for a closed carbon cycle.

To achieve maximum emission reductions considering $\mathrm{CO}_{2}$ of biogenic origin as a limited resource, direct biogas methanation is the most preferred fuel production pathway compared to other 
alternatives investigated in this study. However, given limited suitable resources of biogenic carbon, the potential emission reduction that methanation or biogas upgrading can achieve in the national mobility sector of Switzerland is low (less than 1 million tons of $\mathrm{CO}_{2}$ eq per year), and it requires significant amounts of renewable electricity to produce the hydrogen required by the methanation in a climate-friendly way. Because of the significant amount of electricity required by electrolysis, it should be kept in mind that other than power-to-gas, there are alternative systems that can utilize renewable electricity (e.g., power-to-battery charging of electric vehicles, power-to-heat pump, power-tostationary electricity storage), which can achieve higher emission reduction on the basis of $1 \mathrm{kWh}$ of electricity input. ${ }^{57}$ However utilizing renewable electricity through these other alternative pathways requires the co-existence (in case of power-to-electricityto-battery electric vehicle and power-to-heat pump) and colocation (in case of power-to-stationary electricity storage) of demand and supply, which are not considered in the work of Sternberg and Bardow. ${ }^{57}$ In the former case, when the renewable electricity is generated at times or locations without demand for heat or charging battery electric vehicles, it has to be either curtailed, transmitted and distributed, or stored. In the latter case, if the electricity demand at a different time period is not at the same location as the renewable electricity is generated, the electricity either has to be transmitted and distributed, which may require expansion of grid infrastructure and become challenging in certain cases; alternatively, it could be transformed to other energy carriers easier to be transported and/or stored. As a result, Powerto-gas can play a role to reduce GHG emissions when all these other alternatives of utilizing renewable electricity are not feasible. Further research needs to investigate such temporal and spatial aspects and together with other constraints (e.g., availability of carbon sources) and alternative pathways of utilizing renewable electricity, more realistic technological potential of power-tomethane and associated reduction of GHG emissions should be estimated. In addition, the focus on the Swiss context in this study can be further extended to other regions, for example, by considering the local renewable resources such as solar irradiance and suitable biomass. The approach and data of this study can be applied to assess the decarbonisation potential of the investigated systems in other geographical locations.

\section{Conclusions}

With a system boundary different from previous research and improved understanding of the processes, this study assessed the life cycle GHG emissions of three types of pathways that produce biomethane through biogas upgrading and/or methanation. The GHG emissions of these pathways are compared with alternatives of fuels and vehicles when the product gas is used as fuel in a CNG passenger vehicle. The results show that using product gas produced from both methanation (with PV electricity for electrolysis) and biogas upgrading in a CNG passenger vehicle will result in $27 \%$ to $62 \%$ lower life-cycle GHG erpissions 3eh CNG vehicle fuelled with conventional natural gas, or $41 \%$ to $70 \%$ lower GHG emissions than a vehicle with an internal combustion engine and petrol as fuel. Using electricity with low GHG emissions for electrolysis for the pathways involving methanation - of less than about 152-336 $\mathrm{g} \mathrm{CO}_{2}$ eq per $\mathrm{kWh}$ - is key to ensure lower life cycle GHG emissions than its fossil alternative. Feedstocks resulting in biogas from anaerobic digestion with higher shares of biomethane are preferred, as less hydrogen will be needed for methanation, which can effectively reduce the system life cycle $\mathrm{GHG}$ emissions. Compared to other non-biogenic $\mathrm{CO}_{2}$ sources for methanation, using biowaste as $\mathrm{CO}_{2}$ source can achieve higher overall system emission reductions due to its biogenic origin of $\mathrm{CO}_{2}$. Given limited resource of biogenic $\mathrm{CO}_{2}$, direct biogas methanation can achieve the highest emission reduction among all the systems investigated. Meanwhile, limited resource of suitable biowaste could be the main constraint to the wide deployment of systems investigated in this study, as also discussed in a recent review study of Power-to- $X .^{58}$ Future research is needed to specify where and when the renewable electricity will be generated and available for the analysed biomethane production pathways. Together with constraints of $\mathrm{CO}_{2}$ resource and other alternatives to utilize the renewable electricity, more realistic technology potential can be estimated for the systems investigated in this study. While this study focused on the impact on climate change, other environmental impacts should be considered when comparing different biomethane production pathways and different vehicle types.

\section{Conflicts of interest}

There are no conflicts to declare.

\section{Acknowledgements}

The work was supported by the research funding provided by The Swiss Competence Center for Energy Research (SCCER) - Heat and Electricity Storage (Hae), - Supply of Electricity (SOE) and the SCCER Efficient Technologies and Systems for Mobility, as well as the Energy System Integration (ESI) platform of Paul Scherrer Institute. We would like to thank our colleagues Adelaide Calbry-Muzyka from the Paul Scherrer Institute, Vanessa Burg and Gillianne Bowman from the Swiss Federal Institute for Forest, Snow and Landscape Research, who provided insight and expertise on biomass potential in Switzerland that assisted this research.

\section{References}

1 B. Battke, T. S. Schmidt, D. Grosspietsch and V. H. Hoffmann, Renew. Sustain. Energy Rev., 2013, 25, 240250.

2 J. A. Fonseca, T. A. Nguyen, A. Schlueter and F. Marechal, Energy Build., 2016, 113, 202-226. 

Worlitschek, Energy, 2017, 139, 1173-1187.

J. Xu, R. Z. Wang and Y. Li, Sol. Energy, 2014, 103, 610-638. B. Schaefli, P. Manso, M. Fischer, M. Huss and D. Farinotti, Renew. Energy, 2019, 132, 615-627.

J. Xu, R. Z. Wang and Y. Li, Sol. Energy, 2014, 103, 610-638.

R. Schlögl, C. Abanades, M. Aresta, A. Azapagic, E. A. Blekkan, T. Cantat, G. Centi, N. Duic, E. A. Khamlichi, G. Hutchings, M. Mazzotti, U. Olsbye and H. Mikulcic, Novel carbon capture and utilisation technologies, Research and climate aspects, 2018.

X. Zhang, C. Bauer, C. L. Mutel and K. Volkart, Appl. Energy 2017, 190, 326-338.

W. Liu, Z. Zhang, X. Xie, Z. Yu, K. von Gadow, J. Xu, S. Zhao and Y. Yang, Sci. Rep., 2017, 7, 39857.

N. Aryal, T. Kvist, F. Ammam, D. Pant and L. D. M. Ottosen, Bioresour. Technol., 2018.

Electrochaea, Hydrogenics Europe, NEAS Energy, HMN Gashandel, Insero, BIOFOS and Audi AG, Power-to-Gas via Biological Catalysis (P2G-Biocat) Final Report, 2017.

C. Dannesboe, Catalytic Upgrading of CO2 in Biogas, 2019. M. Specht, J. Brellochs, V. Frick, B. Stürmer and U.

Zuberbühler, in Synthetic Natural Gas from Coal and Dry Biomass, and Power-to-Gas Applications, Wiley Blackwell, 2016, pp. 191-220.

J. Witte, A. Calbry-Muzyka, T. Wieseler, P. Hottinger, S. M. A. Biollaz and T. J. Schildhauer, Appl. Energy, 2019, 240, 359-371.

A. S. Calbry-Muzyka, A. Gantenbein, J. Schneebeli, A. Frei, A. J. Knorpp, T. J. Schildhauer and S. M. A. Biollaz, Chem.

Eng. J., 2019, 360, 577-590.

M. Lehner, R. Tichler, H. Steinmüller and M. Koppe, Powerto-Gas: technology and business models, Springer International Publishing, 2014.

F. Ausfelder, C. Beilmann, M. Bertau, S. Bräuninger, A. Heinzel, R. Hoer, W. Koch, F. Mahlendorf, A. Metzelthin, M. Peuckert, L. Plass, K. Räuchle, M. Reuter, G. Schaub, S. Schiebahn, E. Schwab, F. Schüth, D. Stolten, G. Teßmer, K. Wagemann and K. F. Ziegahn, Chemie-Ingenieur-Technik, 2015, 87, 17-89.

F. Graf, A. Krajete and U. Schmack, Abschlussbericht: Techno-ökonomische Studie zur biologischen Methanisierung bei Power-to-Gas-Konzepten, 2014.

M. Gassner and F. Maréchal, Biomass and Bioenergy, 2009 33, 1587-1604.

M. Götz, J. Lefebvre, F. Mörs, A. McDaniel Koch, F. Graf, S. Bajohr, R. Reimert and T. Kolb, Renew. Energy, 2016, 85, 1371-1390.

J. Witte, J. Settino, S. M. A. Biollaz and T. J. Schildhauer, Energy Convers. Manag., 2018, 171, 750-768.

J. Witte, A. Kunz, S. M. A. Biollaz and T. J. Schildhauer, Energy Convers. Manag., 2018, 178, 26-43.

M. Jentsch, T. Trost and M. Sterner, in 6th International Renewable Energy Storage Conference (IRES 2011), 2011. D. Parra, X. Zhang, C. Bauer and M. K. Patel, Appl. Energy, 2017, 193, 440-454.

T. T. Q. Vo, K. Rajendran and J. D. Murphy, Appl. Energy, , DOI:10.1016/j.apenergy.2018.06.139.

T. T. Q. Vo, D. M. Wall, D. Ring, K. Rajendran and J. D. Murphy, Appl. Energy, 2018, 212, 1191-1202.

S. Wettstein, R. Itten and M. Stucki, .

P2G-Biocat, ANNEX 1 ForskEL 2014-1-12164 Life Cycle
Analysis, Power-to-Gas via Biological Catalysis, 2017. P. Collet, E. Flottes, A. Favre, L. Raynab, HoPierye, Ss CapeedaH and C. Peregrina, Appl. Energy, 2017, 192, 282-295.

D. Wilken, S. Rauh, R. Fruhner-Weiß, F. Strippel, G. Bontempo, A. Kramer, M. Fürst, M. Wiesheu, G. Kedia, A. Mukherjee, C. H. Chanto, S. Siebert, C. Herbes, P. Kurz, V. Halbherr, J. Dahlin and M. Nelles, Digestate as Fertilizer BIOGAS Know-how_4 Application, upgrading and marketing, 2018.

Bundesrecht, Verordnung über die Vermeidung und die Entsorgung von Abfällen, https://www.admin.ch/opc/de/classifiedcompilation/20141858/index.html.

F. Bauer, C. Hulteberg, T. Persson and D. Tamm, Biogas upgrading: Review of commercial technologies

(Biogasuppgradering - Granskning av kommersiella tekniker), 2013.

PSI, Higher methane yield from bio-waste | Our Research | Paul Scherrer Institut (PSI),

https://www.psi.ch/en/media/our-research/highermethane-yield-from-bio-waste, (accessed 26 July 2019). International Organisation for Standardization (ISO), ISO 14040: Life Cycle Assessment - Principles and Framework, 2006.

J. R. Woo, H. Choi and J. Ahn, Transp. Res. Part D Transp. Environ., 2017, 51, 340-350.

C. Bauer, J. Hofer, H. J. Althaus, A. Del Duce and A. Simons, Appl. Energy, 2015, 157, 871-883.

T. Ekvall, in Sustainability Assessment, IntechOpen, 2019. N. Scarlat, F. Fahl, J.-F. Dallemand, F. Monforti and V. Motola, Renew. Sustain. Energy Rev., 2018, 94, 915-930. B. Cox, C. Bauer, A. M. Beltran, D. van Vuuren and C. Mutel, submiited to journal, Curr. under Rev.

O. Thees, V. Burg, M. Erni, G. Bowman and R. Lemm, Biomassenpotenziale der Schweiz für die energetische Nutzung Ergebnisse des Schweizerischen Energiekompetenzzentrums SCCER BIOSWEET, 2017. G. Wernet, C. Bauer, B. Steubing, J. Reinhard, E. MorenoRuiz and B. Weidema, Int. J. Life Cycle Assess., 2016, 21, 1218-1230.

ecoinvent, Allocation cut-off by classification, https://www.ecoinvent.org/database/system-models-inecoinvent-3/cut-off-system-model/allocation-cut-off-byclassification.html.

C. Mutel, Brightway: An open source framework for Life Cycle Assessment, 2017, vol. 2.

IPCC, Climate Change 2013, 2014, vol. 5.

G. Bourgault, Implementation of impact assessment methods in Ecoinvent version 3.4, 2017

M. Stucki, N. Jungbluth and M. Leuenberger, ESU-services Ltd. , 2011, 84.

Vienna University of Technology, Biogas to Biomethane Technology Review, 2012.

Hitachi Zosen Inova, BioMethan Amine Scrubbing Technology Biogas Upgrading with a Heat Driven Process, 2016.

R. Maric and H. Yu, in Nanostructures in Energy Generation, Transmission and Storage, IntechOpen, 2019.

X. Zhang, C. Bauer, C. L. Mutel and K. Volkart, Appl. Energy, 2017, 190, 326-338.

C. Bauer, S. Hirschberg (eds.), Y. Bauerle, S. Biollaz, A. Calbry-Muzyka, B. Cox, T. Heck, M. Lehnert, A. Meier, H.-M. 
Prasser, W. Schenler, K. Treyer, F. Vogel, H. C. Wieckert, X. Zhang, M. Zimmerman, V. Burg, G. Bowman, M. Erni, M. Saar and M. Q. Tran, Potentials, costs and environmental assessment of electricity generation technologies, 2017.

van Vuuren, Environ. Sci. Technol., 2018, 52, 4989-4995.

53 Infras; Prognos; TEP Energy; , Analyse des schweizerischen Energieverbrauchs 2000 - 2014 nach Verwendungszwecken, 2015.

54 Bundesamt für Umwelt BAFU, Beurteilung der Erreichung der sektoralen Zwischenziele 2015 und erste Schätzung zur Zielerreichung 2020, 2020.

55 Bundesamt für Energie BFE, Gesamtenergiestatistik, Endenergieverbrauch nach Energieträgern, https://www.bfs.admin.ch/bfs/de/home/statistiken/energi e/verbrauch.assetdetail.9306221.html.

56 G. Reiter and J. Lindorfer, Int. J. Life Cycle Assess., 2015, 20, 477-489.

57 A. Sternberg and A. Bardow, Energy Environ. Sci., 2015, 8, 389-400.

58 J. C. Koj, C. Wulf and P. Zapp, Renew. Sustain. Energy Rev., 2019, 112, 865-879. 